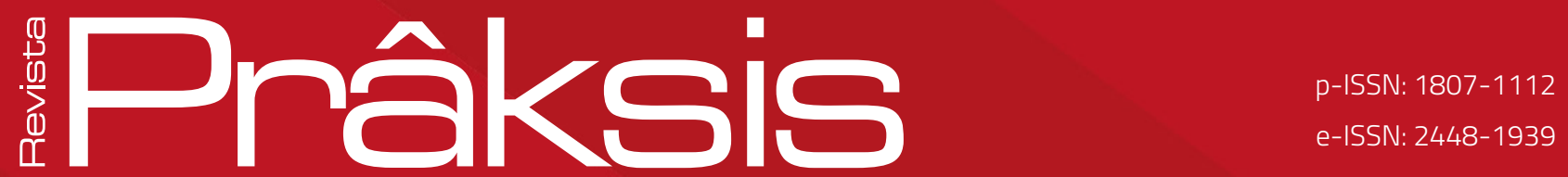

Aprovado em: 15 de março de 2019

Sistema de Avaliação: Double Blind Review RPR |a. 16 | n. 2 | p. 284-300 | mai./ago. 2019

DOI: https://doi.org/10.25112/rpr.v2i0.1923

\title{
"EU NÃO SOU UM HOMEM FÁCIL": SCRIPTS DE GÊNERO E SEXUAIS EM TELA E NA EDUCAÇÃo
}

\section{"I AM NOT AN EASY MAN": GENDER AND SEXUAL SCRIPTS ON SCREEN AND EDUCATION}

\section{Cristiano Eduardo da Rosa}

Licenciado em Letras pela Universidade Feevale e mestrando

em Educação na Universidade Federal do Rio Grande do Sul

Email: cristiano1105@hotmail.com.

\section{Jane Felipe}

Pós-doutora em Cultura Visual pela Universidade de Barcelona.

Professora titular da Faculdade de Educação da Universidade Federal do Rio Grande do Sul.

Email: janefelipe.souza@gmail.com.

\section{Michele Lopes Leguiça}

Licenciada em Educação Especial pela Unipampa e mestranda em

Educação na Universidade Federal do Rio Grande do Sul.

Email: micheleleguica@hotmail.com. 


\section{RESUMO}

Neste estudo analisamos a percepção de estudantes do Ensino Médio com relação aos conceitos de scripts de gênero e scripts sexuais operados no filme francês "Eu não sou um homem fácil", lançado em 2018 pela plataforma Netflix. A partir dos referenciais teóricos dos Estudos de Gênero e dos Estudos Culturais, em especial na perspectiva pós-estruturalista de análise, procuramos compreender de que modo os/as alunos/as são capturados/as pela narrativa da produção audiovisual, fazendo-os questionar ou reafirmar as oposições binárias entre homens e mulheres. Como metodologia, adotamos a exibição do longa-metragem e uma produção escrita acerca do que mais chamou a atenção dos/as jovens no filme podendo ser uma cena, um diálogo, uma frase, uma imagem, etc. Foi possível observar o reconhecimento das expectativas de gênero e sexuais pelos/as jovens, assim como o sentimento de estranhamento e, ao mesmo tempo, familiarização com o enredo do vídeo. Alguns questionamentos foram levantados pelos/ as estudantes, tanto os meninos quanto as meninas, refletindo sobre o que é ser/se fazer homem e mulher na sociedade contemporânea em que vivemos, tendo scripts rígidos e normativos.

Palavras-chave: Scripts de gênero e sexuais. Educação. Equidade.

\section{ABSTRACT}

In this study we analyzed the perception of high school students regarding the concepts of gender scripts and sexual scripts operated in the French film "I am not an easy man", launched in 2018 by the Netflix platform. From the theoretical frameworks of Gender Studies and Cultural Studies, especially in the post-structuralist perspective of analysis, we try to understand how the students are captured by the narrative of audiovisual production, making them question or reaffirm binary oppositions between men and women. As a methodology, we adopted the feature film and a written production about what most attracted the attention of the young people in the film - it could be a scene, a dialogue, a phrase, an image, etc. It was possible to observe the recognition of the gender and sexual expectations of the young, as well as the feeling of estrangement and, at the same time, familiarity with the plot of the video. Some questions were raised by the students, both boys and girls, reflecting on what it is to be / become a man and a woman in the contemporary society in which we live, having rigid and normative scripts.

Keywords: Gender and sexual scripts. Education. Equity. 


\section{PARA INÍCIO DE CONVERSA, NÃO SOMOS PESSOAS FÁCEIS}

Entender a si mesmo enquanto sujeito que é interpelado por marcas de classe, gênero, raça, religião e de orientação sexual, dentre outras, não é uma tarefa muito fácil, principalmente na juventude. Entender o outro também exige, por vezes, um grande esforço e alto grau de empatia, por conta da complexidade dos sujeitos. Porém, em meio a essa complexidade que envolve pensamentos críticos e visões de mundo diferentes, onde conceitos e pensamentos (des)encaixam quando colocados sob ângulos diversos, que variantes interessantes nos (des)encontros e choques movimentam o debate, principalmente sobre identidade e diferença.

Na Educação, essas discussões têm avançado, com alguma dificuldade, especialmente nos últimos anos, em todos os níveis de ensino, devido à onda conservadora que se instalou no país, a partir da retirada do tema gênero/sexualidade do Plano Nacional de Educação (2015). No entanto, acreditando na possibilidade de realizar uma intervenção na qual estudantes percebam como são capturados/as pela norma, principalmente frente às questões relativas ao ser/se fazer homem ou mulher na sociedade contemporânea, é que propomos este nosso estudo.

Operando com filmes como artefatos culturais para sensibilizar e subsidiar problematizações potentes na escola, neste estudo pretendemos tanto destacar o uso do cinema na Educação quanto a importância do debate sobre gênero e sexualidade na instituição de ensino por meio das provocações que o enredo de "Eu não sou um homem fácil", filme francês que estreou na Netflix em abril de 2018, oportuniza aos espectadores.

\section{INGRESSO NA MÃO, VAMOS NOS AJEITANDO NAS POLTRONAS}

Cena 1: Minutos antes do início de um teatro da turma de crianças para as suas famílias, descobre-se que a atriz mirim principal ficou doente.

- Quem quer usar o vestido da Branca de Neve?

- Eu!, responde um menino.

Corte para cena 2: Na cadeira da sala da psicóloga, Damien relembra:

- Eu tinha cinco anos. Meu coração batia pela menina mais bonita da sala que nunca tinha me notado. Eu senti que finalmente ela tinha olhado pra mim. Foi maravilhoso. Ela se chamava Lara. Achei que fosse morrer!".

O filme "Eu não sou um homem fácil" foi lançado mundialmente pela plataforma Netflix em 13 de 
abril de 2018, com legendas em alemão, francês, inglês, italiano e português. É uma produção francesa de 1 hora e 38 minutos, com classificação indicativa de 14 anos e que apresenta a seguinte sinopse: "Um machista inveterado prova de seu próprio veneno ao acordar em um mundo dominado por mulheres, onde entra em conflito com uma poderosa escritora".1

Na história do longa-metragem, que começa pelas cenas descritas acima, um sujeito machista, após bater a cabeça num poste por estar olhando para mulheres do outro lado da rua, acorda em um mundo onde elas expressam os comportamentos e ocupam os lugares comumente relacionados aos homens na sociedade atual, praticando o femismo - um movimento sinônimo ao machismo, porém trocando os gêneros, em que a mulher se sente superior ao homem.

Na realidade em que o protagonista Damien (interpretado pelo ator Vincent Elbaz) acorda, os homens recebem cantadas, são responsáveis pelos afazeres domésticos, lutam pelo "masculinismo" (semelhante ao feminismo), possuem líderes mulheres no trabalho, depilam-se, são dependentes e sentimentais. Ou seja, passa-se a imagem de um mundo onde impera um matriarcado e, ao se relacionar com Alexandra (interpretada pela atriz Marie-Sophie Ferdane), uma escritora que o contrata como agente, o personagem principal percebe mais ainda os status possivelmente invertidos, apesar dele não perder a memória de suas vivências antes do acidente - o que contribui para a dificuldade de compreensão e posicionamento neste novo mundo, não aceitando a forma pela qual a sociedade onde está imerso agora se impõe a ele.

\section{TEORIZAR SOBRE UM HOMEM NADA FÁCIL}

O conceito de gênero pode ser pensando como um "produto de diferentes tecnologias sociais, como o cinema, por exemplo, e de discursos, epistemologias e práticas críticas institucionalizadas, bem como das práticas da vida cotidiana" (LAURETIS, 1994, p. 208). Por meio da narrativa, com tons de humor devido às vivências inusitadas do protagonista e a própria percepção do espectador para com as analogias construídas, o filme permite pensar sobre as desigualdades entre homens e mulheres, tanto em termos de oportunidades quanto em relação ao "amor romântico", embelezamento, maternidade, maus-tratos emocionais, valores éticos e morais.

Considera-se neste estudo o filme como um artefato cultural, pois como destaca Silva (2001, p. 140), o referido conceito "transmite uma variedade de formas de conhecimento que embora não sejam reconhecidos como tais, são vitais na formação de identidade e subjetividade". Para a constituição das

${ }_{1}^{1}$ Disponível em: <http://www.netflix.com/br/title/80175421>. Acesso em: 19 nov. 2018. 
identidades ocorre um processo reiterado de construção que se alicerça nos scripts de gênero (FELIPE, 2019) que podem ser compreendidos como roteiros, definições, normas, apontamentos, às vezes negociáveis, em outras circunstâncias nem tanto, que prescreveriam as condutas dos sujeitos em seus modos de ser homens e mulheres e em suas experiências com a sexualidade.

Segundo Gagnon e Simon (1973), os scripts sexuais se apresentam em três níveis: o intrapsíquico, o interpessoal e o cenário cultural. No primeiro, a conduta se baseia em seu mundo psíquico para operar com sua identidade sexual; já no segundo, a atuação ocorre pela interação com os demais sujeitos, por meio de comunicação e estratégias; e no terceiro, o comportamento está atrelado aos aspectos produzidos pela cultura em que o sujeito está inserido.

No filme aqui analisado, tais scripts vão sendo em alguma medida desnaturalizados aos olhos do personagem principal, propondo ao espectador esse movimento de desconstrução em torno das identidades fixas. Homens e mulheres espectadores são convidados a adentrar no novo universo criado e dirigido por Eleonore Pourriat, que também assina o roteiro com Ariane Fert. Somos convidados/as a olhar para o cotidiano de um ângulo diferente e talvez a principal percepção instigada na história seja a do movimento pela equidade de gênero.

Cabe referir o quanto a arte - neste caso o filme - pode nos fazer pensar, ao propor essa espécie de inversão nas posições de sujeito que supostamente estão estabelecidas, uma vez que a subjetividade não é fixa, mas é um efeito dos discursos, das relações de poder e das técnicas de si (FOUCAULT, 1993). A narrativa acaba se tornando uma grande provocação, desde a apresentação da linguagem corporal, do lugar de privilégio e do sexismo presente, que está em todo lugar e a todo o momento sendo mostrado, mesmo na inversão dos scripts de gênero proposta no filme.

Aspectos físicos e psicológicos são destacados no enredo para falar sobre as diferenças entre homens e mulheres - articuladas com raça, classe social e nacionalidade. Como atentam Meyer e Soares (2005), sempre partimos de pistas e suspeitas quando investigamos algo que nos provoca, desacomoda, instiga ou nos coloca interrogações. Assim, há um movimento de estranhamento e, ao mesmo tempo, de familiarização com as noções de senso comum que nossa sociedade produz, mantém e reproduz, principalmente, sobre os corpos.

Precisamos destacar que a diferença sexual "não é, nunca, simplesmente, uma função de diferenças materiais que não sejam, de alguma forma, simultaneamente marcadas e formadas por práticas discursivas" (BUTLER, 1999, p. 153). De maneira não usual e colocando sob suspeita todas as convenções do que seria um universo masculino ou feminino, "Eu não sou um homem fácil" se propõe a fazer quem assiste ao filme (re)pensar sobre seu comportamento e sua própria identidade como sujeito de um gênero 
e de uma sexualidade.

O comportamento sexual dos personagens também é explorado, na medida em que há interação entre homens e mulheres que tornam os scripts sexuais evidentes. Uma cena que destacamos é quando Damien busca o filho do amigo depois de sua aula de ballet para conversar em uma lanchonete e falar sobre seu pai, mas percebe que o garoto está um pouco estranho e descobre que foi assediado por uma colega no banheiro de sua escola, que o obrigou a fazer sexo oral nela. Tal cena contempla uma situação de assédio que ocorre de forma recorrente com as meninas, vítimas de abuso e exploração sexual, ressaltando que muitas vezes os abusadores são os próprios membros da família. Porém, tratando-se de uma vítima masculina, no caso do filme, o protagonista só consegue ver um menino acuado e que, por ser homem, deveria ter se aproveitado da situação. Ele ainda questiona e ressalta que sempre se tem escolha quando isso acontece, que ninguém é obrigado a fazer algo.

Pensamos aqui na ideia de consentimento e na diferença de valor para ambos os gêneros, sendo impossivel ignorar as estatísticas em todo o mundo dando conta dos altos índices de violência/abuso contra meninas e mulheres. Conforme balanço de denúncias recebidas pelo Disque 100, canal para relatar casos de violação de direitos humanos, entre 2012 e 2016 o Brasil teve mais de 175 mil casos de exploração sexual de crianças e adolescentes. Os números representam a média de quatro casos por hora e, do total dos casos, $67,7 \%$ das crianças e jovens que sofrem abuso e exploração sexuais são meninas, contra $16,52 \%$ dos meninos (FERNANDES, 2017).

Sendo um artefato cultural com um amplo alcance de público, o filme opera com diferentes "modos de endereçamento" (ELLSWORTH, 2001), interpelando tanto homens quanto mulheres. Assim, os scripts são problematizados no longa-metragem e negociam, por meio de sátiras e sutilezas, identidades e lugares de fala e de escuta, na medida propondo novas interrogações que, de certa forma, inverteriam as relações de poder entre os gêneros. Dessa forma, o enredo acaba por estabelecer pontos extremistas acerca dos scripts de gênero, uma vez que enfatizam a todo o momento as diferenças e reforçam conflitos, além de mostrar os movimentos pela equidade de gênero como lutas que não subvertem efetivamente as normas padronizadoras da cultura. Além disso, o marcador binário fica evidente em diversos cenários, seja no trabalho ou na família, entre amigos ou amores, na cultura ou nas políticas públicas, em gerações ou nos maus-tratos emocionais que acontecem a todo momento.

Como desfecho, a produção apresenta Alexandra, em uma briga verbal e física com Damien, que acaba caindo e batendo a cabeça no chão. Ao acordar, sai andando pela cidade enquanto enxerga diversas mulheres lutando pela bandeira do feminismo. Assim, percebemos a mensagem de empatia se concretizando na própria narrativa, surpreendendo espectadores e fazendo nossa imaginação iniciar 
uma nova história onde os scripts de gênero e os scripts sexuais atuam constante e novamente.

\section{A FIM DE COMPREENDER OS MODOS DE ASSISTIR E PENSAR SOBRE O FILME}

Para a produção do material empírico desta pesquisa exibimos o filme "Eu não sou um homem fácil" para estudantes de duas turmas de $2^{\circ}$ ano do Ensino Médio de uma escola estadual do município de Parobé, no Vale do Paranhana, Rio Grande do Sul. A atividade ocorreu na última semana do mês de novembro de 2018, durante aulas de Língua Portuguesa, em parceria com a docente da referida disciplina da instituição.

A proposta era dos/as alunos/as assistirem ao filme, sem conhecimentos prévios sobre a produção, e, logo após a exibição, escreverem um comentário sobre o que mais Ihes chamou a atenção na história - podendo ser uma cena, um diálogo, uma frase, uma imagem, etc. O objetivo era capturar as percepções dos/as estudantes acerca das temáticas que a película aborda por meio de uma produção escrita livre, para analisarmos, posteriormente, tendo conhecimento somente do gênero e da idade dos/as alunos/ as autores/as.

Pelo filme ser uma obra com classificação indicativa para maiores de 14 anos, tivemos a preocupação de realizar esta pesquisa com estudantes acima desta faixa etária - por isso a opção do ano escolar escolhido. No total, 45 participantes assistiram e comentaram o filme, sendo destes 21 alunos e 24 alunas. Juntamente com a proposta de participação no estudo, comprometemo-nos com as turmas a disponibilizar o resultado com a análise da pesquisa e realizar um debate aberto sobre a produção cinematográfica após a análise das suas produções escritas.

0 foco da investigação que fizemos teve por base observar como as questões de gênero e sexualidade aparecem nas produções escritas pelos/as discentes, e de que forma os/as estudantes percebiam ou não os binarismos e as desigualdades entre homens e mulheres. As produções apontaram diversas percepções interessantes que foram analisadas à luz dos Estudos de Gênero e dos Estudos Culturais.

\section{ENTRE TAKES, CUTS E CLOSE-UPS: SCRIPTS EM ANÁLISE}

Tomando emprestado o subtítulo do mais recente livro da pesquisadora e professora Guacira Lopes Louro, que é uma referência nos estudos de gênero, sexualidade e queer, intitulado "Flor de Açafrão" (2017), nesta seção nos aproximamos com a proposta da referida obra, estabelecendo relações entre 
produções cinematográficas com aprendizagens sobre gênero e sexualidade. Aqui, tais conexões são vindas de adolescentes e seus olhares sobre o filme "Eu não sou um homem fácil".

A realidade apresentada pelo longa-metragem francês é retratada pelos/as estudantes que participaram desta pesquisa como um mundo inverso, invertido, avesso, ao contrário, estranho, oposto, uma realidade alternativa e paralela. Parte dos/as alunos/as chegou a comentar acerca da impossibilidade ou mesmo inviabilidade de uma realidade como a apresentada na produção em nossa sociedade atual.

De maneira geral, a maioria dos/as estudantes comenta em suas produções sobre a inversão de papéis masculinos e femininos. No entanto, Louro (2014, p. 28) observa que, embora a expressão "papel" seja comum para indicar funções convencionadas aos gêneros, a concepção de "papéis de homem" ou "papéis de mulher" podem se mostrar redutoras ou simplistas. Segundo a referida autora

Discutir a aprendizagem de papéis masculinos e femininos parece remeter a análise para os indivíduos e para as relações interpessoais. As desigualdades entre os sujeitos tenderiam a ser consideradas no âmbito das interações face a face. Ficariam sem exame não apenas as múltiplas formas que podem assumir as masculinidades e as feminilidades, como também as complexas redes de poder que (através das instituições, dos discursos, dos códigos, das práticas e dos símbolos...) constituem hierarquias entre os gêneros.

Tendo em vista essas considerações, trabalhamos nesta pesquisa com os conceitos de scritps de gênero - discutidos por Felipe (2019) na perspectiva dos Estudos Culturais - e de scripts sexuais problematizados por Gagnon (2006) em sua perspectiva sociológica. De acordo com Gagnon (2006, p. 21), que trabalhou com a temática da sexualidade e suas influências sociais, a teoria sobre o conceito de roteiros sexuais parte do pressuposto que "os indivíduos usam sua habilidade interativa, bem como material da fantasia e mitos culturais, para desenvolver roteiros (com deixas e diálogos apropriados), como um modo de organizar seu comportamento sexual".

Para início das análises, observamos que o filme provocou, principalmente nas alunas, uma reflexão acerca dos maus-tratos que as mulheres que sofrem, sinalizando para a naturalização de algumas violências. Uma aluna comentou sobre como a inversão da ótica para essas práticas a fez pensar no quanto as mulheres têm "aceitado" essas situações².

\footnotetext{
${ }^{2}$ Os nomes dos/as estudantes que assinam as produções escritas desta pesquisa são fictícios.
} 


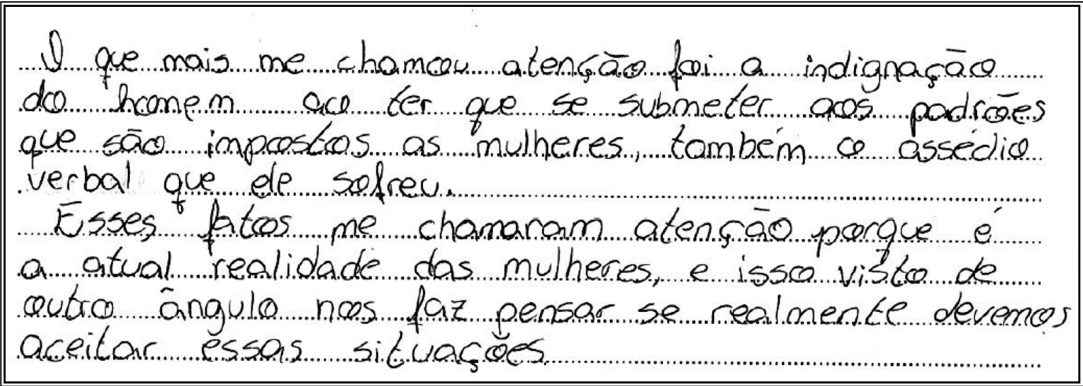

Marlene, 16 anos (27/11/2018).

A questão do assédio também chamou a atenção dos/as estudantes, ainda mais por ser praticado no filme pelas mulheres sobre os homens. De acordo com o Código Penal (BRASIL, 1940), Título VI de Crimes contra a Dignidade Sexual, Capítulo I dos Crimes contra a Liberdade Sexual, Art. 216-A, incluído pela Lei nº 10.224, de 15 de 2001, considera-se assédio sexual o ato de "constranger alguém com o intuito de obter vantagem ou favorecimento sexual, prevalecendo-se o agente da sua condição de superior hierárquico ou ascendência inerentes ao exercício de emprego, cargo ou função".

Destacamos aqui a campanha "Chega de Fiu Fiu", criada pelo site Think Olga em 2013 para lutar contra o assédio sexual em locais públicos que, além de ter lançado o documentário "Chega de Fiu Fiu" em maio de 2018, com direção de Amanda Kamanchek e Fernanda Frazão, mantém um site na tentativa de mapear os lugares mais incômodos e até perigosos para mulheres no Brasil. A página convida as leitoras a compartilhar seus depoimentos caso já tenham sofrido assédio ou algum outro tipo de violência, podendo também ser possivel dividir histórias que tenham testemunhado, mostrando que juntas poderão reunir dados importantes para combater o problema. ${ }^{3}$

Segundo pesquisa realizada pelo Instituto DataFolha em novembro de $2017,42 \%$ das entrevistadas disseram já terem sofrido assédio sexual, sendo que um terço delas relata já ter passado por isso na rua, e um quinto, no transporte. 0 estudo também mostra que quando mais nova, maior o assédio; assim como mulheres orientais, pretas e pardas, mais escolarizadas e mais ricas o problema é mais sentido.

Outra questão que emergiu nas produções foi envolvendo a importância da empatia, muitas vezes não praticada por aqueles que não vivem determinadas situações. Uma aluna destacou a maneira como o filme aborda a realidade feminina e comenta da falta de um olhar por sujeitos que não vivenciam a experiência de ser mulher numa sociedade machista.

\footnotetext{
${ }^{3}$ Disponivel em: <http://chegadefiufiu.com.br>. Acesso em: 28 nov. 2018.
} 


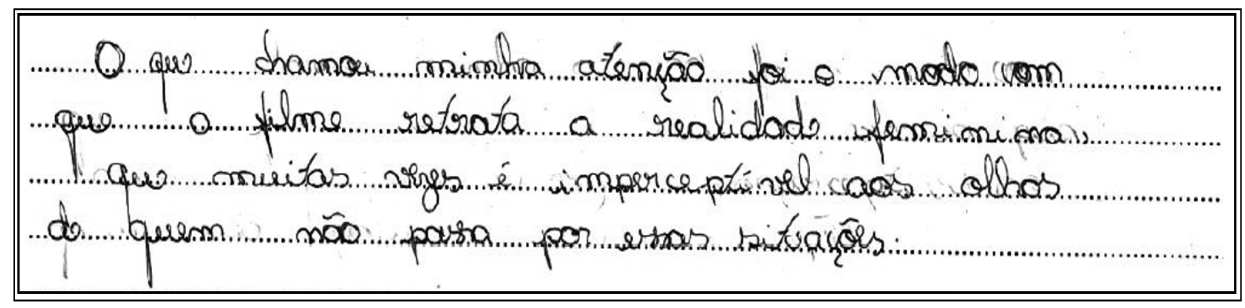

Rosângela, 17 anos (28/11/2018).

As pequenas e quase imperceptiveis violências diárias sofridas pelas mulheres acabam sendo, por vezes, naturalizadas. Os micro machismos consistem nessas pequenas ações, muitas vezes em formas de piadas, em interrupções de suas falas, em explicações óbvias quando os homens tentam "traduzir" o que uma mulher acabou de dizer. Ou ainda em outras se travestem na forma daquilo que chamamos de violência "benévola", comportamentos de controle que se disfarçam em proteção.

As produções escritas pelos/as estudantes também destacaram o estranhamento acerca dos homens tendo que lutar por seus direitos, algo que não existe em nossa realidade, uma vez que vivemos em uma sociedade que corrobora os privilégios masculinos, impondo uma inferioridade feminina em muitas esferas (salários mais baixos para elas, por exemplo).

Atualmente há diversos movimentos que objetivam justamente envolver os homens na luta pela equidade de gênero juntamente com as mulheres. Há duas pesquisas em especial: a primeira chamada "O papel do homem na desconstrução do machismo", desenvolvida pelo Instituto Avon / Locomotiva e lançada no final de 2016; e a segunda, "Precisamos falar com os homens? Uma jornada pela igualdade de gênero", que apresenta um levantamento que identifica como as mulheres percebem o papel dos homens na sua vida e na sociedade hoje, apontando as principais tensões culturais que geram sofrimento e desigualdade entre os gêneros.

Juntamente com este segundo estudo, foi lançado em 2017 um documentário de mesmo nome que procura aproximar os homens desse debate, objetivando mostrar que a igualdade de gênero é uma questão que afeta aos sujeitos de maneira geral e que, sendo assim, é benéfica a homens e mulheres. ${ }^{4}$

A ONU Mulheres e o portal PapodeHomem (2016, p. 63) elencam um caminho por onde os homens poderiam transformar suas atitudes e crenças sobre gênero: (i) afeto; (ii) exposição ao sofrimento das mulheres; (iii) paternidade; (iv) espiritualidade; (v) acesso a espaços seguros e de acolhimento para homens; (vi) exaustão e infelicidade profissional; e (vii) choque: sofrimento profundo, rupturas e crises.

${ }^{4}$ Disponivel em: <http://www.youtube.com/watch?v=oq-WybTYKqw>. Acesso em: 28 nov. 2018. 
A construção da identidade masculina estereotípica, de acordo com o mesmo material (2016), poderia ser expressa em nove ensinamentos básicos: cultura do herói; expressão: violência; heterossexualidade; restrição emocional; capital viril; pertencimento ao grupo; sexo; trabalho; e provedor. Já a construção da identidade feminina se dividiria em quatro ensinamentos complementares: pureza, cuidado, fragilidade e beleza.

Uma produção escrita por um aluno nos chamou a atenção ao mencionar a possibilidade de não aceitar se estivesse inserido naquela realidade que o protagonista do filme viveu após bater sua cabeça.

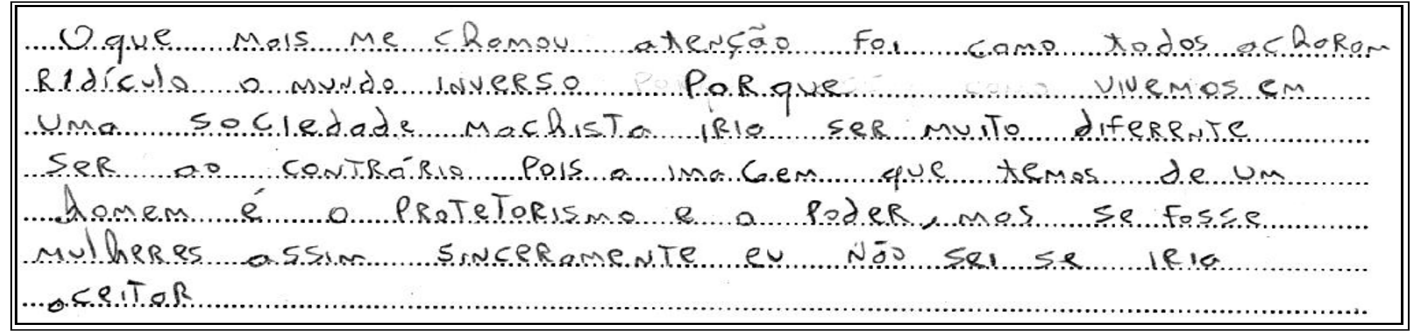

Estevão, 16 anos (27/11/2018).

Lembramos aqui do documentário "The Mask You Live In" - "A Máscara em que Você Vive" em português. Lançado em 2015, o filme escrito, produzido e dirigido por Jennifer Siebel Newsom está disponível na plataforma Netflix e aborda o machismo naturalizado na sociedade apresentando entrevistas com especialistas e acadêmicos, a fim de debater como essa noção de "macho" pode afetar psicologicamente as crianças, os jovens e, no futuro, os adultos. ${ }^{5}$

Refletindo sobre as produções escritas dos/as alunos/as, foi possivel perceber como alguns/ algumas até identificam a problemática do machismo em nossa cultura, mas ao mesmo tempo há um forte sentimento de estranhamento quando a situação se dá de forma contrária ao habitual - e esse sentimento é maior do que a possibilidade de cogitar haver um equilíbrio nessa relação de poder entre homens e mulheres.

A conexão entre o oprimido e o opressor também fica bastante evidenciada no filme, a partir de uma perspectiva que reitera as oposições binárias entre os gêneros a partir dessa estratégia de "inversão" das representações de ser/se fazer masculino e feminino. A mulher, comumente humilhada e inferiorizada pelo homem, aparece como uma pessoa dominadora e tirânica sobre ele.

Os/as estudantes destacaram bastante a questão do corpo como foi apresentada no filme,

${ }^{5}$ Disponível em: <http://www.netflix.com/br/title/80076159>. Acesso em: 4 dez. 2018. 
principalmente na cena em que Alexandra reclama dos pelos no peitoral de Damien. Alunos e alunas citaram como isso acontece ao contrário, quando as mulheres são criticadas quando deixam seus pelos crescerem, especialmente nas pernas e nas axilas.

O sentimento de culpa também foi apresentado em uma produção escrita por um aluno, que afirmou estar repensando algumas atitudes suas a partir das provocações que o filme lhe causou.

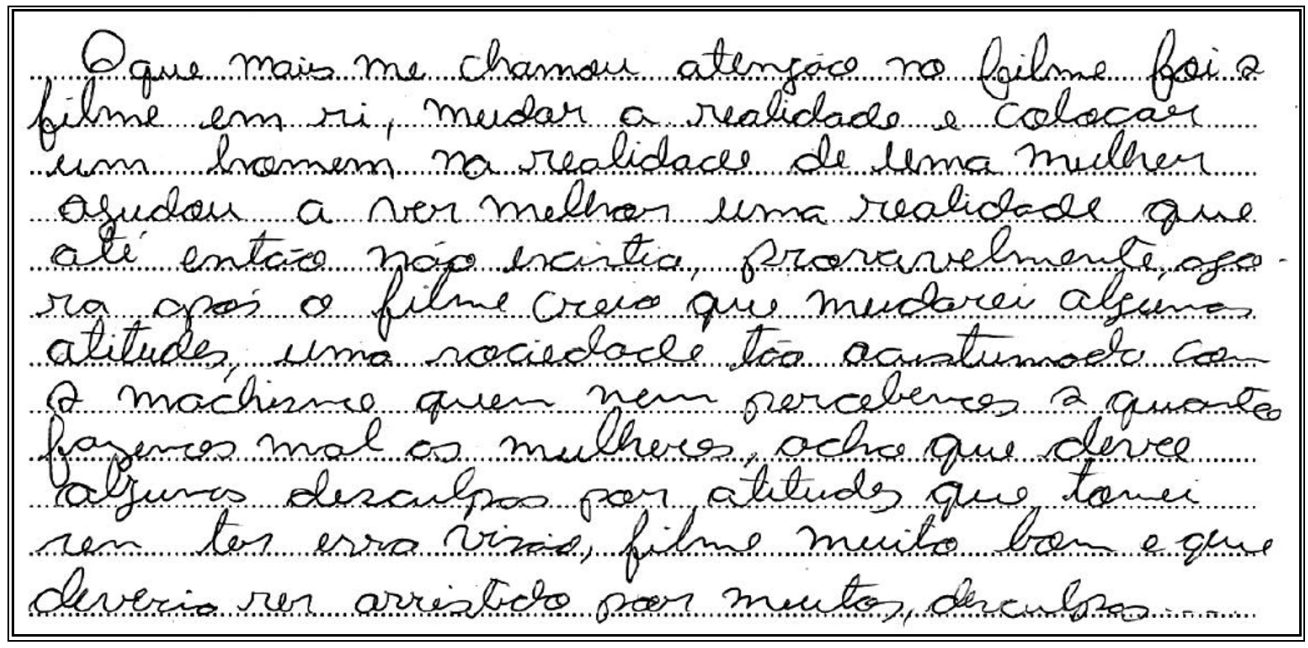

Elias, 17 anos (27/11/2018).

Chamou-nos a atenção também algumas confusões conceituais expressas pelos alunos, como a ideia de que o machismo seria o oposto de feminismo - dois movimentos que são bem distintos. Enquanto o primeiro coloca a mulher como um ser inferior ao homem, o segundo luta pela igualdade de direitos entre os gêneros.

Como Lauretis (1986, p. 2) destaca, com o feminismo surge "uma nova maneira de pensar sobre a cultura, sobre a linguagem, a arte, a experiência e sobre o próprio conhecimento". Pinto (2010, p. 15) salienta que o movimento feminista, surgido nas últimas décadas do século XIX, "é um movimento que produz sua própria reflexão crítica, sua própria teoria", ou seja, faz-se necessário compreender que a sociedade militante que o impulsionou foram as próprias mulheres.

A principal intenção dos Estudos Feministas, de acordo com Louro (2014, p. 151), foi

tomar a mulher como sujeito/objeto de estudos - ela que fora ocultada ou marginalizada na produção científica tradicional. [...] denunciaram lacunas, apontaram desvios ou criticaram interpretações das grandes teorias; buscaram incorporar as mulheres e, mais adiante, as relações de gênero a essas formulações. 
Desde o seu início, o movimento feminista tem passado por quatro ondas - termo que corresponde às gerações dos pensamentos feministas - sendo a mais recente muito influenciada e potencializada pela internet. Tais ondas passaram por perfis igualitaristas, diferencialistas, interseccionlistas e antiessencialistas, sempre dialogando sobre homens e mulheres e as suas relações. Nesse sentido, Louro (2014, p. 163) também afirma que "as mulheres e os homens feministas precisam estar atentas/os às relações de poder que se inscrevem nas várias dinâmicas sociais - das quais elas e eles tomam parte".

Outra questão que foi apresentada em uma produção de um aluno diz respeito a uma interpretação equivocada acerca da ideia de no filme haver "mulheres querendo ser homens e homens querendo ser mulheres". Pensamos que aqui o estudante fez uma alusão às pessoas trans, vista ainda por muitos como uma questão que se resume à puramente troca de gênero motivada por algum distúrbio emocional ou mental.

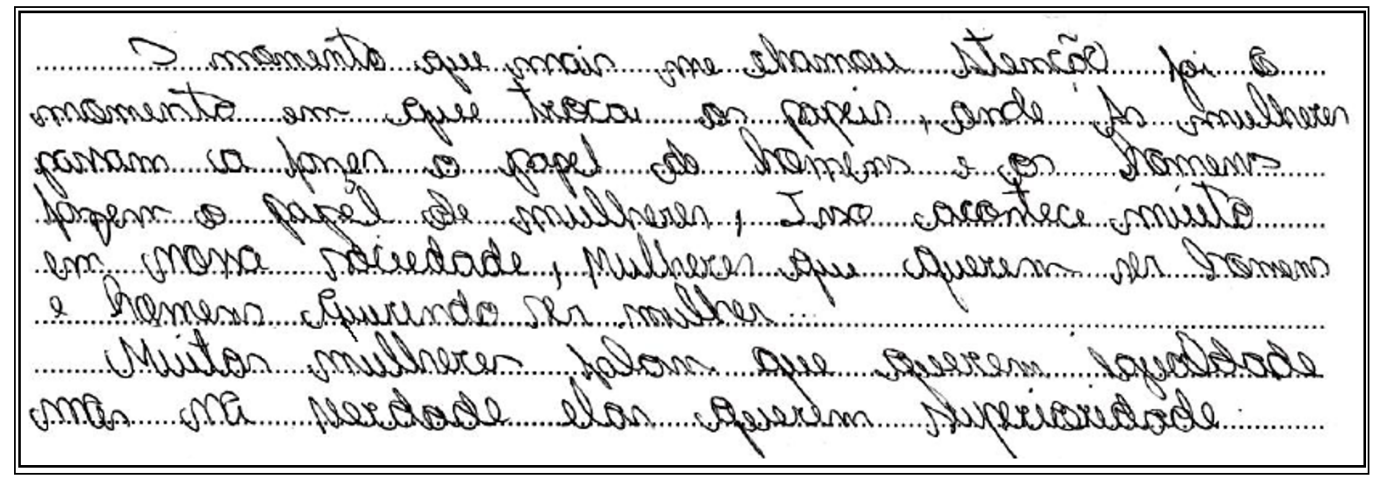

Jairo, 16 anos (28/11/2018).

Além do aluno acima, outros três destacaram uma situação imaginada por eles em que no nosso mundo atual, as mulheres estão querendo mais que igualdade, mas também uma superioridade em relação aos homens: "muitas mulheres dizem que querem igualdade e justiça, quando na verdade querem superioridade e certo privilégio" (Carlos, 17 anos); "as mulheres do nosso tempo não querem igualdade, mas sim querem superioridade" (Eduardo, 17 anos); "nem todos os homens são machistas, assim como nem todas as mulheres querem só igualdade, e sim mais poder" (Flávio, 18 anos).

Observamos também em algumas produções uma confusão na compreensão do espectador quanto à trama do filme, e isso nos remete ao pensamento de uma dificuldade de empatia de quem assiste ao filme para com os problemas de desigualdade da sociedade. Outro ponto destacado pela maioria dos/as estudantes foi que, mesmo os personagens estando em uma realidade de inversão de posturas 
masculinas e femininas, a desigualdade continua e segue os olhares diferentes acerca de scripts impostos pela sociedade.

Cabe aqui ressaltar que o filme provocou em alguns alunos homens uma interpretação um tanto equivocada, quando apontaram para o fato das mulheres quererem uma superioridade em relação aos homens. Nesse sentido, é preciso pontuar que os conceitos de igualdade e equidade não são sinônimos nesse contexto. Conforme nos aponta Azevedo (2013, p. 131), ambos os termos "são princípios fundamentais para a entificação de sociedades que se querem justas (...) igualdade e equidade constituem valores essenciais para a construção de políticas públicas voltadas para a promoção da justiça social e da solidariedade".

Enquanto a igualdade se refere a oferecer aos sujeitos as mesmas oportunidades, a equidade visa adaptar as oportunidades e deixá-las mais justas a todos/as. Portanto, ao se falar de gênero, por exemplo, seria preciso considerar as diferenças e, dessa forma, seria mais correto utilizarmos o termo "equidade de gênero", tendo em vista o princípio da justiça por trás dos mecanismos que propõe diminuir as desigualdades entre homens e mulheres.

Assim, tanto a igualdade quanto a equidade de gênero são por vezes encaradas como uma espécie de superioridade quando requerida pelas mulheres, e talvez se justifique pela naturalização da existência de uma desigualdade histórica entre homens e mulheres desde os tempos mais remotos. As diferenças de gênero são construídas de maneira tão sutil desde a infância que, ao chegar na idade adulta, os sujeitos já não se reconhecem mais como portadores de singularidades criadas culturalmente pela sociedade.

Joan Scott (1989, p. 21) desenvolve sua definição para o termo com base em duas afirmações: "o gênero é um elemento constitutivo de relações sociais baseado nas diferenças percebidas entre os sexos, e o gênero é uma forma primeira de significar as relações de poder". Assim, é preciso destacar como os conceitos de igualdade e equidade não são sinônimos nesse contexto. Conforme nos aponta Azevedo (2013, p. 131), ambos os termos "são princípios fundamentais para a entificação de sociedades que se querem justas (...) igualdade e equidade constituem valores essenciais para a construção de políticas públicas voltadas para a promoção da justiça social e da solidariedade".

Enquanto a igualdade se refere a oferecer aos sujeitos as mesmas oportunidades, a equidade visa adaptar as oportunidades e deixá-las mais justas a todos/as. Portanto, ao se falar de gênero, por exemplo, seria preciso considerar as diferenças e, dessa forma, seria mais correto utilizarmos o termo "equidade de gênero", tendo em vista o princípio da justiça por trás dos mecanismos que propõe diminuir as desigualdades entre homens e mulheres. Dessa forma, não é suficiente ter a consciência acerca do "nível" de desigualdade que existe na sociedade em que vivemos, é preciso que se promovam práticas 
sobre a construção histórica que diz respeito à igualdade. (AZEVEDO, 2013).

\section{CONSIDERAÇÕES PARA ALÉM DA SUBIDA DOS CRÉDITOS FINAIS}

Neste estudo, o filme "Eu não sou um homem fácil" foi operado como artefato cultural, como potência à sensibilização para a discussão das temáticas de corpo, gênero e sexualidade com estudantes do Ensino Médio. Observamos que, ao perceber a mulher atuando nos espaços e nas funções comumente associados/as ao homem, os/as estudantes que participaram desta pesquisa compreendem com facilidade a inversão de práticas com base nas (re)produções de suas vivências reais, mas, ao mesmo tempo, externam uma estranheza que leva a uma quase confissão de não aceitar ou concordar com o que é apresentado, até afirmando não caber em suas vivências tais mudanças.

A experiência de visualizar uma realidade em que as desigualdades entre gênero se invertem e colocam homens e mulheres nos lugares um do outro permitiu aos/às jovens refletirem sobre quem são, o que fazem e como o fazem em relação ao tratamento acerca das relações de gênero e os princípios de equidade e igualdade. O filme, como artefato cultural operando na Educação, foi potente para problematizar as questões de comportamento individual e coletivo como sociedade contemporânea que atribui a sujeitos masculino e femininos roteiros que, quando negados, sofrem sanções.

Longe de um enfim ao presente debate, o filme "Eu não sou um homem fácil" nos mostra como realmente não somos homens e nem mulheres fáceis, pois somos sujeitos complexos, envoltos em uma rede ampla de discursos, sujeitos aos acontecimentos históricos, sociais e culturais que vão nos constituindo. No geral, não somos uma sociedade fácil, em especial por ainda operarmos com perspectivas tão machistas, racistas, LGBTfóbicas.

Frente a barreiras e desprestígios vindos de discursos políticos e de parte da população, assim como acusações de doutrinação, que ignoram toda uma construção científica, cultural e histórica do conceito de gênero (como campo conceitual, de disputa e tensões), ainda existimos, resistimos e persistimos em nossos estudos para demonstrar como a equidade de gênero desde a infância poderia mudar o mundo em que vivemos para melhor.

\section{REFERÊNCIAS}

AZEVEDO, Mário Luiz Neves de. Igualdade e equidade: qual é a medida da justiça social? Avaliação,

Campinas; Sorocaba, SP, v. 18, n. 1, p. 129-150, mar. 2013. 
BRASIL. Presidência da República, Casa Civil, Subchefia para Assuntos Jurídicos. Código Penal, Decretolei $n^{\circ}$ 2.848, de 7 de dezembro de 1940. Disponivel em: <http://www.planalto.gov.br/ccivil_03/DecretoLei/Del2848.htm>. Acesso em: 11 dez. 2018.

BUTLER, Judith. Corpos que pesam: sobre os limites discursivos do sexo. In: LOURO, Guacira. 0 corpo educado: Pedagogias da Sexualidade. Belo Horizonte: Autêntica, 1999. p. 151-172.

ELLSWORTH, Elizabeth. Modos de endereçamento: uma coisa de cinema; uma coisa de educação também. In: SILVA, Tomaz Tadeu da (org.). Nunca fomos humanos. Belo Horizonte: Autêntica, 2001. p. 8-76.

FELIPE, Jane. Scripts de gênero, sexualidade e infâncias: temas para a formação docente. In: ALBUQUERQUE, Simone Santos; FELIPE, Jane; CORSO, Luciana Vellinho (orgs.). Para Pensar a Docência na Educação Infantil. Porto Alegre: Evanfrag, 2019. p . 238-250.

FERNANDES, Sarah. Com quatro casos de exploração sexual de crianças por hora, Brasil debate prevenção. RBA, Rede Brasil Atual, 22 de maio de 2017. Disponível em: <http://www.redebrasilatual. com.br/cidadania/2017/05/com-quatro-casos-de-exploracao-sexual-de-criancas-por-hora-brasildebate-prevencao>. Acesso em: 26 abr. 2018.

FOUCAULT, Michel. Verdade e subjetividade. Revista de Comunicação e Linguagem. Lisboa, n. 19, 1993. GAGNON, John H. Uma interpretação do desejo. Rio de Janeiro: Garamond, 2006.

GAGNON, John; SIMON, William. Sexual Conduct: The Sexual Sources of Human Sexuality. Chicago: Aldine, 1973.

INSTITUTO AVON; LOCOMOTIVA. 0 papel do homem na desconstrução do machismo. Disponivel em: <http://agenciapatriciagalvao.org.br/wp-content/uploads/2016/12/Pesquisa-FSM_2016.pdf>. Acesso em: 28 nov. 2018.

INSTITUTO DATAFOLHA. Assédio sexual entre as mulheres. PO 813942. 29 e 30/11/2017. Disponivel em: <http://media.folha.uol.com.br/datafolha/2018/01/11/ bfed1c72cc0eff5f76027203648546c5bbe9923c.pdf>. Acesso em: 28 nov. 2018.

LAURETIS, Teresa De. A tecnologia do gênero. In: HOLLANDA, Heloisa (Org.). Tendências e impasses: o feminismo como crítica da cultura. Rio de Janeiro: Rocco, 1994. p. 206-237. 
LAURETIS, Teresa De. Feminist Studies/Critical Studies: Issues, terms, and contexts. In: LAURETIS, Teresa De (ed.) Feminist Studies/Critical Studies. Bloomington e Indianapolis: Indiana University Press, 1986.

LOURO, Guacira Lopes. Flor de Açafrão: takes, cuts e close-ups. Belo Horizonte: Autêntica, 2017.

LOURO, Guacira Lopes. Gênero, sexualidade e educação: Uma perspectiva pós-estruturalista. 16. ed. Petrópolis: Vozes, 2014.

MEYER, Dagmar E. Estermann; SOARES, Rosângela de Fátima. Modos de ver e se movimentar pelos caminhos da pesquisa pós-estruturalista em educação: o que podemos aprender com e a partir de um filme. In: COSTA, Marisa Vorraber; BUJES, Maria Isabel Edelweiss. Caminhos investigativos III: riscos e possibilidades de pesquisar nas fronteiras. Rio de Janeiro: DP\&A, 2005. p. 23-44.

ONU MULHERES; PAPODEHOMEM. Precisamos falar com os homens? Uma jornada pela igualdade de gênero. Disponivel em: <http://issuu.com/onumulheresbrasil/docs/relat__rio_onu_eles_por_elas_ pesqui>. Acesso em: 28 nov. 2018.

PINTO, Céli Regina Jardim. Feminismo, história e poder. Rev. Sociol. Polít., Curitiba, v. 18, n. 36, p. 1523, jun. 2010.

SILVA, Tomaz Tadeu da. Documentos de identidade: uma introdução às teorias currículo. Belo Horizonte: Autêntica, 2001. 